\title{
LEI DE ACESSO À INFORMAÇÃO: UMA ANÁLISE DOS PORTAIS E SÍTIOS ELETRÔNICOS OFICIAIS DAS PREFEITURAS DO RN
}

\author{
M. G. M. MORAIS e L. C. B. GUERRA \\ Instituto Federal de Educação, Ciência e Tecnologia do Rio Grande de Norte \\ marizemedeiros@hotmail.com, guerra04@gmail.com
}

Artigo submetido em 01/11/2015 e aceito em 09/12/2015

DOI: $10.15628 /$ empiricabr.2015.3832

\begin{abstract}
RESUMO
A Lei $n^{\circ} .12 .527 / 2011$, conhecida por Lei de Acesso à Informação, tem por objetivo implementar a cultura de acesso na administração pública, segundo o entendimento de que as informações produzidas pelo Estado possuem finalidade pública e, sendo um bem público, deverá estar acessível a todos. O presente estudo tem por objetivo analisar os sítios eletrônicos oficiais e portais da transparência mantidos pelas prefeituras do território do Mato Grande, estado do Rio Grande do Norte, para verificar a adequação das informações disponibilizadas na internet com os critérios estabelecidos na Lei de Acesso à Informação. Quanto à metodologia, este estudo enquadra-se em uma pesquisa aplicada, de objetivo descritivo/exploratório e abordagem quantitativa, cujo instrumento é um questionário com 24 perguntas baseadas nos $\operatorname{artigos} 6^{\circ}$ ao $10^{\circ}$ da Lei de Acesso à Informação. Fizeram parte da amostra apenas os municípios do território do Mato Grande/RN com população igual ou superior a 10.000 habitantes. Os resultados obtidos apontam a dificuldade dos municípios em se cumprir os requisitos mínimos da LAI e, consequentemente, não estão prontas para atender a demanda da sociedade por informações públicas, seja em virtude de problemas administrativos, operacionais e pela ausência da cultura de acesso nessas entidades.
\end{abstract}

PALAVRAS-CHAVE: Lei de Acesso à Informação, Transparência, Controle Social.

\section{ACCESS TO INFORMATION LAW: AN ANALYSIS ON OFFICIAL SITES OF RIO GRANDE DO NORTE'S MUNICIPALITY}

\begin{abstract}
Brazilian Law 12527/2011, known as the Access to Information Law, aims to implement the culture of access in public administration, according to the understanding that the information produced by the state has public purpose and, being a public good, should be accessible to all. The objective of this study is to analyze the official electronic and transparency portals maintained by the prefectures of Mato Grande region, in Rio Grande do Norte/Brasil, to verify the adequacy of the information made available on the internet with the criteria established in this law. About the methodology, this study is part of an applied research, with a descriptive/exploratory objective and a quantitative approach, whose instrument is a questionnaire with 24 questions based on articles 6 to 10 of Access to Information Law. Only the municipalities in the territory of Mato Grande/RN with a population equal to or greater than 10,000 inhabitants were included in the sample. The results obtained point to the difficulty of municipalities in meeting the minimum requirements of law and, consequently, are not ready to meet the demand of society for public information, either due to administrative problems, operational and lack of access culture in these entities
\end{abstract}

KEYWORDS: Access to Information Law, Transparency, Social control.

EmpiricaBR, Ano 1, vol. 2 


\section{INTRODUÇÃO}

Nos últimos anos, tem se discutido em todo o mundo a adoção de boas práticas de governança na gestão pública, a qual pressupõe administrar com responsabilidade, transparência e incentivo ao controle social na aplicação dos recursos públicos. No Brasil, a amplitude desta discussão decorreu principalmente da promulgação da Lei $\mathbf{n}^{\circ}$. 131/2009, conhecida por Lei da Transparência Pública, a qual se constitui em um adendo à Lei de Responsabilidade Fiscal, ao incluir novos dispositivos de transparência aos anteriormente previstos no seu artigo 48; e, posteriormente com a Lei $\mathrm{n}^{\circ}$. 12.527/2011, conhecida por Lei de Acesso à Informação, que regulamenta o artigo $5^{\circ}$, inciso XXXIII da Constituição Federal, garantindo o exercício do direito de acesso à informação a todo e qualquer cidadão brasileiro.

A Lei 12.527/2011 tem por objetivo implementar a cultura de acesso na administração pública, segundo o entendimento de que as informações produzidas pelo Estado possuem finalidade pública e, sendo um bem público, deverá estar acessível a todos. Para tanto, a Lei de Acesso à Informação traz dispositivos que orientam a sua implementação, incluindo os procedimentos operacionais, para a garantia do acesso à informação.

No entanto, a implantação de uma política de acesso às informações tem representado um grande desafio às entidades públicas, pois, para a sua eficiência, se faz necessária não somente a publicação de normas e a readequação de procedimentos, mas também promover transformações a nível cultural, com a geração de novos valores e novas práticas direcionadas à prerrogativa de acesso à informação prevista na Constituição Federal.

Nesse contexto, o presente estudo possui como objetivo analisar os sítios eletrônicos oficiais e portais da transparência mantidos pelas prefeituras do território do Mato Grande, estado do Rio Grande do Norte, para verificar a adequação das informações disponibilizadas na internet com os critérios estabelecidos na Lei de Acesso à Informação.

De acordo com o Plano Territorial de Desenvolvimento Rural Sustentável (2010), o território do Mato Grande/RN é formado por dezesseis municípios: Bento Fernandes, Caiçara do Norte, Ceará-Mirim, Jandaíra, Jardim de Angicos, João Câmara, Maxaranguape, Parazinho, Pedra Grande, Poço Branco, Pureza, Rio do Fogo, São Bento do Norte, São Miguel do Gostoso, Taipu e Touros. Com a ocupação de uma área de $5.986,20 \mathrm{Km}^{2}$, esta região apresenta uma população de 226.714 habitantes, segundo dados do Censo 2010 do IBGE.

O presente trabalho será realizado em virtude da relevância do tema acerca da transparência pública no Brasil, que ganhou destaque após a entrada em vigor da Lei da Transparência Pública (Lei Complementar ${ }^{\circ}{ }^{131 / 2009)}$ e da Lei de Acesso à Informação - LAI (Lei $n^{\circ}$ 12.527/2011), mas que, decorridos três anos da regulamentação desta última pelo Decreto $\mathrm{n}^{\circ}$ 7.724/2012, o acesso às informações 
públicas ainda não encontra-se devidamente implementadas nos órgãos públicos relacionados pela referida legislação.

Um levantamento de dados realizado pela Controladoria Geral da União, entre fevereiro e março de 2015, apontou que, em todo o país, apenas 36\% dos municípios com população acima de 100 mil habitantes possui a Lei de Acesso à Informação regulamentada. No âmbito local, em uma recente análise feita pelo MP/RN, MPF/RN, com o apoio da CGU, verificou-se que, dos 167 municípios do Rio Grande do Norte, apenas 31\% (52 municípios) estão com seus portais de transparência atualizados.

Em face da obrigatoriedade do cumprimento dessa legislação pelos órgãos públicos de todos os níveis de poder, este estudo se caracteriza como um incentivo ao fortalecimento dos mecanismos de controle social, como também estimular o desenvolvimento de uma gestão pública responsável e transparente, necessária para pleno exercício da democracia.

O presente artigo tem cinco seções: após a introdução, tem-se na seção 2 um levantamento acerca do direito de acesso à informação no Brasil e no mundo, como também uma discussão acerca dos principais pontos da Lei de Acesso à Informação (12.527/2011). Na seção 3, serão apresentados os procedimentos metodológicos adotados na pesquisa, cujos resultados serão apresentados e discutidos na seção 4 . Por último, a seção 5, traz as considerações finais do estudo.

\section{REVISÃO BIBLIOGRÁFICA}

\subsection{O direito de acesso à informação no Brasil e no mundo}

Em uma sociedade democrática, as diversas relações sociais são marcadas pela necessidade de se fazer escolhas. Portanto, o cidadão devidamente informado tem maiores possibilidades de se beneficiar em sua vida particular e social, seja por decidir pela alternativa mais vantajosa para si ou por conhecer e ter acesso a outros direitos essenciais, como a saúde, educação e benefícios sociais (CGU, 2011), como também possibilitar o monitoramento das tomadas de decisões dos governantes que afetam a vida em sociedade (ANDI, 2009).

Deste modo, ao reduzir a informação disponível, o governo acaba minando a participação cidadã nos processos democráticos. A informação, assim como a publicidade, são princípios indispensáveis para a consolidação da transparência e, consequentemente, da democracia. (BERNARDES, SANTOS E ROVER, 2013).

Segundo as premissas da Nova Gestão Pública, o governo deve atuar conforme os interesses dos cidadãos, não se voltar para o atendimento dos próprios interesses. Nesse contexto, a nova gestão pública traz consigo a ênfase nos conceitos de transparência, controle social e accountability, a fim de conduzir o governo e a sociedade para o exercício de uma administração participativa, democrática, orientada para resultados e focada no interesse público.

A transparência na gestão pública significa tornar viável a maior participação da sociedade na gestão e fiscalização da aplicação dos recursos públicos. Matias-Pereira 
(2008) afirma que a transparência é um dos requisitos de controle da sociedade civil sobre o estado, como também essa mesma sociedade vem se preocupando e exigindo maior transparência na gestão pública, através do combate à corrupção e da cobrança da responsabilidade dos gestores públicos.

Santos (2005), diz que a transparência na Administração Pública, como um pressuposto para a gestão democrática depende, essencialmente, do grau e da forma como se dá o acesso dos agentes econômicos e da sociedade organizada, e do próprio cidadão, à informação que sustenta os processos decisórios e garante o exercício dos direitos dos administrados. Deste modo, pode-se concluir que o acesso às informações públicas é fundamental para que o controle social seja exercido com eficácia, fortalecendo também a cidadania.

Platt Neto et al (2007) nos mostra que a transparência pressupõe três elementos ou dimensões: a publicidade, a compreensibilidade e a utilidade para decisões. Estas são características qualitativas desejáveis das informações divulgadas pelo governo, onde cada elemento complementa e interage com os outros para que a transparência seja plenamente propiciada.

Na visão de Sales (2012), vivenciamos atualmente a fase da ciberdemocracia, decorrente do uso de novas tecnologias pelo setor público, em especial a Internet, para divulgar, expor, relacionar, fiscalizar e criar. A transparência proporcionada pelo ciberespaço torna-se um importante meio de controle da Administração Pública, que não somente diminui a distância entre os cidadãos e o Poder Público, ao permitir o acompanhamento das ações governamentais por aqueles, como também amplia a voz do cidadão, ao abrir a possibilidade de exigir o cumprimento dos serviços oferecidos e a responsabilização dos agentes públicos pela eventual irregularidade.

Partindo desses pressupostos, em várias partes do mundo, o acesso às informações sob a guarda do Estado está sendo cada vez mais reconhecido como um direito fundamental. Mais de 90 países possuem leis que o regulamentam, como também diversos organismos internacionais, como a Organização das Nações Unidas ONU e a Organização dos Estados Americanos- OEA, reconheceram o direito fundamental de acesso às informações mantidas pelos órgãos públicos, mediante tratados, convenções e pactos internacionais, dos quais o Brasil foi signatário. Além disso, as transformações sociais ocorridas no final do século XX, decorrentes da democratização de vários países e dos avanços nas tecnologias de informação e comunicação foram responsáveis por modificar completamente a relação das sociedades com a informação e o uso que fazem dela(CGU, 2015). Inclusive, a própria existência de leis de transparência pública é um indicativo do amadurecimento das suas respectivas sociedades democráticas (RESENDE E NASSIF, 2015).

No Brasil, o acesso à informação pública está previsto no capítulo I da Constituição Federal de 1988 - dos Direitos e Deveres Individuais e Coletivos especialmente no inciso XXXIII do artigo $5^{\circ}$, reconhecendo-o como um direito fundamental do cidadão, ao dispor que "todos têm direito de receber dos órgãos públicos informações de seu interesse particular, ou de interesse coletivo ou geral, que serão prestadas no prazo da lei, sob pena de responsabilidade, ressalvadas aquelas cujo 
sigilo seja imprescindível à segurança da sociedade e do Estado". No texto constitucional, este assunto também é tratado no art. $5^{\circ}$, inciso XIV, art. $37, \S 3^{\circ}$, inciso II e art. 216, $\S 2^{\circ}$. No entanto, estes dispositivos somente ganharam maior efetividade com a edição da Lei Federal n ${ }^{\circ}$. 12.527/2011 - Lei de Acesso à Informação, regulada pelo Decreto $\mathrm{n}^{\mathrm{o}}$. 7.724/2012, definindo normas, procedimentos e prazos para o atendimento das solicitações feitas pelos cidadãos a respeito das informações mantidas pelas instituições públicas.

Entretanto, antes da Lei $\mathrm{n}^{\circ}$. 12.527/2011, diversas normas e iniciativas administrativas já contemplavam a garantia do direito de acesso à informação no país, tais como a Lei de Arquivos (Lei no 8.159/91), a Lei do Habeas Data (Lei nº. 9.507/97), a Lei do Processo Administrativo (Lei $n^{\circ}$ 9.784/99), a Lei de Responsabilidade Fiscal (Lei Complementar nº 101/2000), a criação do Portal da Transparência do Governo Federal (2004) e a Lei da Transparência Pública (Lei Complementar $n^{\circ} .131 / 2009$ ), que entraram em vigor com o propósito de tornar as ações de governo mais transparentes à população, como, por exemplo, ao dar publicidade aos atos administrativos e às informações sobre a execução orçamentária e financeira das instituições públicas.

A Lei $n^{\circ}$. 8.159/91 instituiu a Política Nacional de Arquivos Públicos e Privados e dispõe sobre a organização e administração dos arquivos, como também do acesso e do sigilo aos documentos públicos, delegando ao Poder Público o dever de cuidar da gestão documental e da proteção aos documentos de arquivos, como instrumento de apoio à administração, à cultura, ao desenvolvimento científico ecomo elementos de prova e informação. No artigo $4^{\circ}$ da referida lei, é ratificado o direito constitucional de acesso às informações públicas, ao determinar que "Todos têm direito a receber dos órgãos públicos informações de seu interesse particular ou de interesse coletivo ou geral, contidas em documentos de arquivos, que serão prestadas no prazo da lei, sob pena de responsabilidade, ressalvadas aquelas cujo sigilo seja imprescindível à segurança da sociedade e do Estado, à inviolabilidade da intimidade, da vida privada, da honra e da imagem das pessoas". (BRASIL, 1991).

Por sua vez, o rito processual do Habeas Data foi instituído pela Lei $n^{\circ}$. 9.507/97, assegurando o direito constitucional de conhecer dados relativos à sua pessoa que estejam nos bancos de dados governamentais ou públicos, como também atualizar ou corrigir a referida informação, caso seja necessário.

Em 1999, a Lei $n^{\circ} .9 .784$ instituiu normas sobre o processo administrativo no âmbito da Administração Federal direta e indireta. No artigo $2^{\circ}$, parágrafo único, inciso $\mathrm{V}$, deverá ser observado o critério de divulgação oficial dos atos administrativos, ressalvadas as hipóteses de sigilo previstas na Constituição.

Em 05 de maio de 2000, surge a Lei de Responsabilidade Fiscal - LRF, sancionada pela Lei Complementar $\mathrm{n}^{\circ}$. 101, tornando-se um dos marcos fundamentais da política de transparência pública brasileira, ao estabelecer nos seus artigos 48 e 49, os instrumentos de transparência na gestão fiscal, que são as leis orçamentárias - Plano Plurianual, Lei de Diretrizes Orçamentárias e Lei Orçamentária Anual; prestação de contas e respectivo parecer prévio, o Relatório Resumido de Execução Orçamentária e Relatório de Gestão Fiscal, aos quais deverá ser dada ampla divulgação, inclusive em meios eletrônicos de acesso público, inclusive a versão simplificada destes 
documentos, de modo que o cidadão comum tenha acesso e condições de entendimento do conteúdo dos documentos, para que tenha condições de avaliar o desempenho do gestor público na administração dos recursos, estimulando a participação da sociedade no processo de gestão fiscal.

Após a publicação da Lei de Responsabilidade Fiscal, temos a criação do Portal da Transparência do Governo Federal, em 2004. Também considerado um dos grandes marcos da política de transparência do governo, o Portal da Transparência é um instrumento de controle social e transparência pública, por meio do qual a sociedade pode acompanhar e fiscalizar os gastos do Poder Executivo Federal, no que tange à correta aplicação dos recursos públicos.

A Lei Complementar nº. 131/09, conhecida por Lei da Transparência Pública, consiste em um adendo à Lei de Responsabilidade Fiscal, alterando o artigo 48 da referida lei, incluindo dispositivos que ampliam a transparência na gestão dos recursos públicos, ao exigir a publicação em tempo real de informações sobre a execução orçamentária e financeira em meio eletrônico de amplo acesso ao público. Com isso, a sociedade passou a ter a oportunidade de acompanhar deforma concomitante a execução do orçamento público, facilitando a detecção de irregularidades mediante o exercício do controle social.

Consolidando as políticas de transparência governamental adotadas nos últimos anos, decorrentes da implementação da Nova Gestão Pública no país, foi publicada a Lei $\mathrm{n}^{\mathrm{o}} .12 .527$ - Lei de Acesso à Informação, instituindo o acesso às informações públicas como regra e o sigilo como uma exceção, assegurando o pleno exercício do direito de acesso previsto na Carta Magna.

\subsection{A Lei no. 12.527/2011 (Lei de Acesso à Informação)}

Seguindo a tendência de mais de 90 países que possuem leis regulamentadoras do direito de acesso à informação, a Lei $\mathrm{n}^{\circ} .12 .527$ garantiu maior efetividade ao direito de acesso, ao definir a forma, os procedimentos para se obter o acesso às informações públicas, como também os prazos a serem observados, tanto pelo poder público, quanto pela sociedade, para o seu fornecimento.

Aprovada em 18 de novembro de 2011 e em vigor desde 16 de maio de 2012, a Lei de Acesso à Informação deverá ser observada pelos órgãos e entidades públicas da administração direta e indireta dos poderes Executivo, Legislativo e Judiciário da União, Estados, Distrito Federal e Municípios. Aplica-se ainda às entidades privadas sem fins lucrativos que recebam recursos públicos, para a realização de ações de interesse público.

A fim de garantir o direito fundamental de acesso à informação, a LAI estabelece procedimentos que deverão ser executados conforme os princípios da administração pública e das seguintes diretrizes: observância da publicidade como preceito geral e do sigilo como exceção; divulgação de informações de interesse público, independentemente de solicitações; utilização de meios de comunicação viabilizados pela tecnologia da informação; fomento ao desenvolvimento da cultura de 
transparência na administração pública e desenvolvimento do controle social da administração pública (BRASIL, 2011). Para tanto, os órgãos e entidades públicas deverão assegurar a gestão transparente da informação, de modo a possibilitar o amplo acesso e sua divulgação; a proteção da informação, garantindo a sua disponibilidade, autenticidade e integridade; e a proteção da informação sigilosa e pessoal, observando também a sua disponibilidade, autenticidade e integridade, e eventual restrição de acesso (CONTROLADORIA GERAL DA UNIÃO, 2014).

Além do estabelecimento do dever de divulgação proativa das informações públicas, a LAI ainda define, no $\S^{\circ}$ do art. $8^{\circ}$, um rol mínimo de informações de interesse coletivo ou geral, quais sejam:

I - registro das competências e estrutura organizacional, endereços e telefones das respectivas unidades e horários de atendimento ao público;

II - registros de quaisquer repasses ou transferências de recursos financeiros;

III - registros das despesas;

IV - informações concernentes a procedimentos licitatórios, inclusive os respectivos editais e resultados, bem como a todos os contratos celebrados; $\mathrm{V}$ - dados gerais para o acompanhamento de programas, ações, projetos e obras de órgãos e entidades e;

VI - respostas a perguntas mais frequentes da sociedade. (BRASIL, 2011).

Estas informações deverão ser divulgadas em todos os meios e instrumentos legítimos de que dispuserem, mas que deverá ser feita obrigatoriamente em sítios oficiais da rede mundial de computadores (internet), os quais deverão conter os requisitos mínimos, tais como: ferramentas de pesquisa de conteúdo, possibilidade de gravação de relatórios em diversos formatos, indicação do local e das instruções para contato eletrônico ou telefônico com o órgão e adoção de medidas necessárias para garantir a acessibilidade do conteúdo às pessoas com deficiência. No entanto, os municípios com população de até 10.000 (dez mil) habitantes ficam dispensados da divulgação obrigatória do rol mínimo de informações na internet, mantendo-se apenas a obrigatoriedade prevista na Lei de Responsabilidade Fiscal e na Lei Complementar $n^{\circ} .131 / 2009$, para a divulgação, em tempo real, das informações pertinentes às receitas e despesas em seus respectivos sítios oficiais.

Do mesmo modo em que estão estabelecidos os mecanismos de Transparência Ativa (divulgação proativa de informações, sem necessidade de solicitação formal), a LAI também define os procedimentos de Transparência Passiva (divulgação de informações quando formalmente solicitado) a serem adotados pelos órgãos e entidades públicas. Para o atendimento das solicitações da sociedade, deverá ser implantado um Serviço de Informações ao Cidadão (SIC) físico, com uma estrutura necessária para orientar sobre os procedimentos de acesso, informar sobre a tramitação de documentos e protocolizar documentos e requerimentos de acesso à informação. Além do espaço físico, os órgãos e entidades públicas deverão disponibilizar, em seus sítios oficiais na internet, um meio eletrônico para que o cidadão possa fazer o requerimento de informações, seja por e-mail ou formulário eletrônico.

A solicitação deverá conter a identificação do requerente e a especificação da informação que se deseja obter, sendo vedada a exigência de justificativa do pedido pela parte solicitante. $\mathrm{O}$ serviço de fornecimento de informações é gratuito, exceto no 
caso de reprodução de documentos, onde poderá ser cobrado apenas o valor referente ao ressarcimento dos custos com serviços e materiais empregados.

Ao receber o pedido, o órgão ou entidade pública deverá responder imediatamente, caso a informação já esteja disponível, ou em até 20 dias, prorrogáveis por mais 10 dias, comunicando ao requerente a data, o local e o modo para atendimento do pedido, como também apresentar as razões para a negativa total ou parcial de acesso à informação solicitada.

As restrições do acesso à informação referem-se às que digam respeito à segurança da sociedade (à vida, à segurança ou à saúde da população) ou do Estado (risco à defesa e à soberania nacional; segurança de instituições ou de altas autoridades e seus familiares; atividades de inteligência, de investigação ou de fiscalização em andamento), como também as informações pessoais, relativas à intimidade, à vida privada, à honra e à imagem das pessoas. $\mathrm{O}$ prazo máximo para restringir o acesso às informações pessoais é de 100 (cem) anos, quando poderá ser acessada apenas pelos próprios indivíduos, sendo que por terceiros dependerá das situações previstas em lei ou por consentimento expresso da pessoa referida. Por sua vez, as informações sigilosas poderão ser classificadas pelas autoridades competentes em ultrassecretas - 25 (vinte e cinco) anos, secretas - 15 (quinze) anos e reservadas - 5 (cinco) anos.

A Lei de Acesso à Informação foi regulamentada no âmbito do Poder Executivo Federal pelo Decreto no .7 .724 , de 16 de maio de 2016. Já o artigo 45 da LAI delega aos Estados, Distrito Federal e Municípios o estabelecimento de regras específicas sobre a matéria, especialmente quanto ao disposto no art. $9^{\circ}$ e na Seção II do Capítulo III. A regulamentação local poderá ser feita mediante edição de lei ou decreto, observando as normas gerais previstas na lei nacional.

Angélico (2012) aponta a necessidade de engajamento da população para se efetivar a implementação de um regime de acesso às informações públicas. A participação mais ativa de setores da sociedade interessados em temas mais gerais, tais como a boa governança, promoção de direitos e combate à corrupção, possibilita a ampliação e fortalecimento da accountability democrática.

No entanto, Cavalcanti, Damasceno e Souza Neto (2013) ressaltam que apenas disponibilizar a informação em ambientes eletrônicos não possibilita ao usuário a capacidade de fazer inferências acerca de seu conteúdo. Os governos deverão aprender a registrar, catalogar, organizar as informações e disponibilizá-las da forma mais adequada na Internet para que os cidadãos possam compreender e chegar à conclusão acerca das informações governamentais ali expostas.

\section{METODOLOGIA}


Com o objetivo de analisar o cumprimento das exigências da LAI nos sítios eletrônicos oficiais e portais da transparência mantidos pelas prefeituras do território do Mato Grande, estado do Rio Grande do Norte, o presente artigo se enquadra em uma pesquisa aplicada, de objetivo exploratório/descritivo. A abordagem de pesquisa é quantitativa, aonde, consoante Zanella (2012), o pesquisador procura medir e quantificar os resultados da investigação, sendo apropriada para medir tanto opiniões, atitudes e preferências como comportamentos.

O universo de pesquisa abrange as entidades submetidas à Lei $n^{\circ}$. 12.527/2011 e a amostra, definida pelo método de amostragem não-probabilística por conveniência, compreenderá os órgãos do Poder Executivo Municipal do território do Mato Grande.

Vale destacar que, segundo o $\S^{\circ}$ do art. $8^{\circ}$ da Lei $n^{\circ} 12.527 / 2011$, apenas os municípios com mais de 10.000 (dez mil) habitantes são obrigados a divulgar informações na internet. Assim, dos 16 municípios que fazem parte da região do Mato Grande, apenas sete atendem a esse requisito, listadas a seguir:

Tabela 1 - Relação dos Municípios da Região do Mato Grande com população acima de 10 mil habitantes

\begin{tabular}{l|r}
\hline \multicolumn{1}{c|}{ Município } & População \\
\hline Ceará-Mirim & 68.141 \\
João Câmara & 32.227 \\
Touros & 31.089 \\
Poço Branco & 13.949 \\
Taipu & 11.836 \\
Maxaranguape & 10.441 \\
Rio do Fogo & 10.059 \\
\hline
\end{tabular}

Fonte: IBGE, 2010.

Quanto aos procedimentos técnicos, foi realizada uma pesquisa bibliográfica e documental, consultando artigos, relatórios, documentos e pesquisas de avaliação, para desenvolver os estudos relacionados ao tema em questão. Para o levantamento dos dados, foi consultado, via página de buscas na internet (http://www.google.com), o sítio eletrônico correspondente a cada município abrangido pela pesquisa.

Após a identificação dos sítios eletrônicos, foi realizada a observação direta e sistemática das páginas, com o objetivo de verificar se o município observou o cumprimento do mínimo exigido nos artigos $6^{\circ}$ ao $10^{\circ}$ da Lei $n^{\circ} 12.527 / 2011$, mediante a aplicação de um questionário estruturado com 24 questões dicotômicas (sim/não), baseadas nos referidos artigos da LAI.

\section{RESULTADOS E DISCUSSÕES}


Após a aplicação do questionário nos sítios eletrônicos oficiais e portais da transparência das prefeituras municipais listadas na Tabela 1, foram obtidos os seguintes percentuais de cumprimento da Lei de Acesso à Informação, apresentadas no Gráfico 1, a seguir.

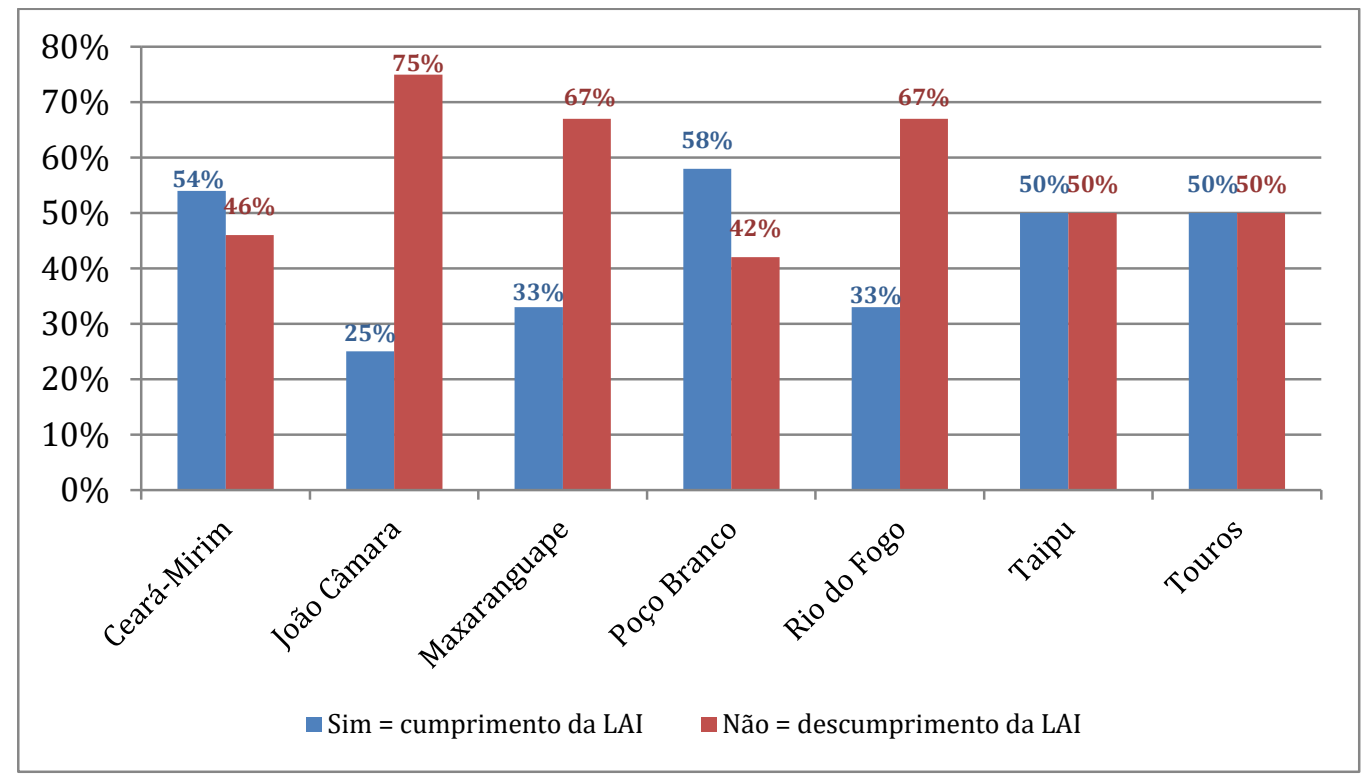

Gráfico 1 - Índices do cumprimento dos requisitos da LAI pelos municípios do Mato Grande/RN, em seus sítios eletrônicos oficiais e portais da transparência. Fonte: Elaborado pelos autores (2015).

Pelo Gráfico 1, percebe-se a dificuldade dos municípios em cumprir todos os requisitos mínimos da Lei de Acesso à Informação quanto à transparência ativa. Dos sete municípios selecionados, três - João Câmara, Maxaranguape e Rio do Fogo, possuem o índice de respostas "não", correspondente aos requisitos da LAI que foram descumpridos, bem superior ao índice de respostas "sim", referente aos itens da LAI que foram cumpridos. Em outros dois municípios - Taipu e Touros, houve um empate entre as respostas "sim” e "não". Já os municípios de Ceará-Mirim e Poço Branco foram os únicos a obterem resultados positivos, com percentuais de 54\% e 58\%, respectivamente, de cumprimento à LAI.

Destaque-se ainda que alguns dos itens analisados não somente encontram previsão na LAI, como também já foram contemplados em outras legislações que o antecederam, como, por exemplo, a Lei de Responsabilidade Fiscal e sua posterior alteração pela Lei Complementar nº. 131/2009.

Tabela 2 - Percentual das respostas por pergunta do questionário.

\begin{tabular}{l|c|r}
\hline \multicolumn{1}{c|}{ Pergunta } & Sim & Não \\
\hline $\mathbf{1}-$ O município possui sítio oficial? & $\mathbf{8 6 \%}$ & $\mathbf{1 4 \%}$ \\
\hline $\mathbf{2}-$ O município possui Portal da Transparência? & $\mathbf{1 0 0 \%}$ & $\mathbf{0 \%}$ \\
\hline
\end{tabular}




\begin{tabular}{|c|c|c|}
\hline 3- O sítio possui uma área específica de "Acesso à Informação"? & $43 \%$ & $57 \%$ \\
\hline $\begin{array}{l}4 \text { - Encontra-se disponível, no sítio eletrônico, a Lei ou o Decreto Municipal } \\
\text { que regulamenta o direito de acesso à informação no âmbito local? }\end{array}$ & $\mathbf{0 \%}$ & $100 \%$ \\
\hline $\begin{array}{l}\mathbf{5} \text { - Encontram-se definidas quais são as informações sigilosas e da informação } \\
\text { pessoal, observada a sua autenticidade, integridade e eventual restrição de } \\
\text { acesso? }\end{array}$ & $\mathbf{0 \%}$ & $100 \%$ \\
\hline $\begin{array}{l}\text { 6-Está disponível a apresentação de metas e indicadores propostos para a } \\
\text { avaliação dos programas, projetos e ações do referido órgão público? }\end{array}$ & $29 \%$ & $71 \%$ \\
\hline $\begin{array}{l}7 \text { - Encontram-se disponíveis os dados gerais para o acompanhamento de } \\
\text { programas, ações, projetos e obras de órgãos e entidades? }\end{array}$ & $29 \%$ & $71 \%$ \\
\hline 8 - Estão disponíveis os resultados de inspeções e auditorias? & $\mathbf{0 \%}$ & $100 \%$ \\
\hline $\begin{array}{l}9 \text { - São divulgadas as prestações e tomadas de contas realizadas pelos órgãos } \\
\text { de controle interno e externo? }\end{array}$ & $\mathbf{0 \%}$ & $100 \%$ \\
\hline $\begin{array}{l}\mathbf{1 0} \text { - Encontram-se disponibilizadas as prestações de contas dos exercícios } \\
\text { anteriores? }\end{array}$ & $29 \%$ & $71 \%$ \\
\hline $\begin{array}{l}11 \text { - Há informações referentes a procedimentos licitatórios, inclusive os } \\
\text { respectivos editais, resultados e os contratos celebrados? }\end{array}$ & $\mathbf{0 \%}$ & $100 \%$ \\
\hline $\begin{array}{l}\text { 12-Está disponível o registro das competências e estrutura organizacional, } \\
\text { endereços e telefones das respectivas unidades e horários de atendimento ao } \\
\text { público? }\end{array}$ & $57 \%$ & $43 \%$ \\
\hline $\begin{array}{l}13 \text { - Consta algum espaço com respostas a perguntas mais frequentes da } \\
\text { sociedade? }\end{array}$ & $14 \%$ & $86 \%$ \\
\hline 14-O sítio contém ferramenta de pesquisa de conteúdo? & $57 \%$ & $43 \%$ \\
\hline $\begin{array}{l}15 \text { - Estão registrados quaisquer repasses ou transferências de recursos } \\
\text { financeiros? }\end{array}$ & $100 \%$ & $\mathbf{0 \%}$ \\
\hline 16 - Estão disponíveis os registros das despesas? & $100 \%$ & $\mathbf{0 \%}$ \\
\hline $\begin{array}{l}17 \text { - O sítio possibilita a gravação de relatórios em diversos formatos } \\
\text { eletrônicos, inclusive abertos e não proprietários, tais como planilhas e texto, } \\
\text { de modo a facilitar a análise das informações? }\end{array}$ & $71 \%$ & $29 \%$ \\
\hline $\begin{array}{l}18 \text { - O sítio possibilita o acesso automatizado por sistemas externos } \\
\text { estruturados e legíveis por máquina? }\end{array}$ & $86 \%$ & $14 \%$ \\
\hline $\begin{array}{l}19 \text { - Divulga, em detalhes, os formatos utilizados para estruturação da } \\
\text { informação? }\end{array}$ & $0 \%$ & $100 \%$ \\
\hline $\begin{array}{l}20 \text { - São garantidas a autenticidade e a integridade das informações } \\
\text { disponíveis para acesso? }\end{array}$ & $100 \%$ & $\mathbf{0 \%}$ \\
\hline 21 - As informações disponíveis para acesso são atualizadas? & $71 \%$ & $29 \%$ \\
\hline $\begin{array}{l}22 \text { - Foram adotadas as medidas necessárias para garantir a acessibilidade de } \\
\text { conteúdo para pessoas com deficiência? }\end{array}$ & 0\% & $100 \%$ \\
\hline $\begin{array}{l}23 \text { - Há a indicação do local e instruções que permitam ao interessado } \\
\text { comunicar-se, por via eletrônica ou telefônica, com o órgão ou entidade } \\
\text { detentora do sítio? }\end{array}$ & $43 \%$ & $57 \%$ \\
\hline $\begin{array}{l}\text { 24-Foi disponibilizada a alternativa de encaminhamento de pedidos de acesso } \\
\text { pela internet, através do seu sítio oficial? }\end{array}$ & $14 \%$ & $86 \%$ \\
\hline
\end{tabular}

Fonte: Elaborado pelos autores (2015).

As questões de 1 a 3 eram referentes à existência de sítio eletrônico e portal da transparência, como também um link específico denominado "Acesso à Informação". Nesta etapa, todos os municípios dispõem de Portal da Transparência, justamente por também ser uma obrigação imposta pela LRF e sua posterior alteração (a Lei 
Complementar $\left.n^{\circ} .131 / 2009\right)$, a qual passou a exigir a publicação de receitas e despesa na internet em tempo real, desde o dia 27 de maio de 2011, aos municípios com população entre 50.000 e 100.000 habitantes; e desde o dia 27 de maio de 2013, aos municípios com população inferior a 50.000 habitantes.

Em relação aos sítios oficiais, apenas não foi possível localizar o sítio eletrônico oficial do município de João Câmara, concernente ao Poder Executivo Municipal.

No que se refere ao link específico para o "Acesso à Informação", em apenas $43 \%$ dos sítios pesquisados foram localizados um link com esta nomenclatura, mas que, em alguns municípios, este link se encontrava no Portal da Transparência e em outros, na página inicial do sítio oficial. De acordo com o Guia para criação da seção de acesso à informação nos sítios eletrônicos dos órgãos e entidades estaduais e municipais (CGU, 2013), é recomendável que a divulgação do máximo de informações de interesse público seja organizada e centralizada em seção específica nos sítios eletrônicos dos órgãos e entidades, com o objetivo de oferecer ao cidadão um padrão uniforme de acesso, que facilite a localização e obtenção das informações. Caso prefiram, também poderá ser utilizado o modelo de banner "Acesso à Informação" criado pelo Governo Federal reforçar ainda mais a identidade visual do link.

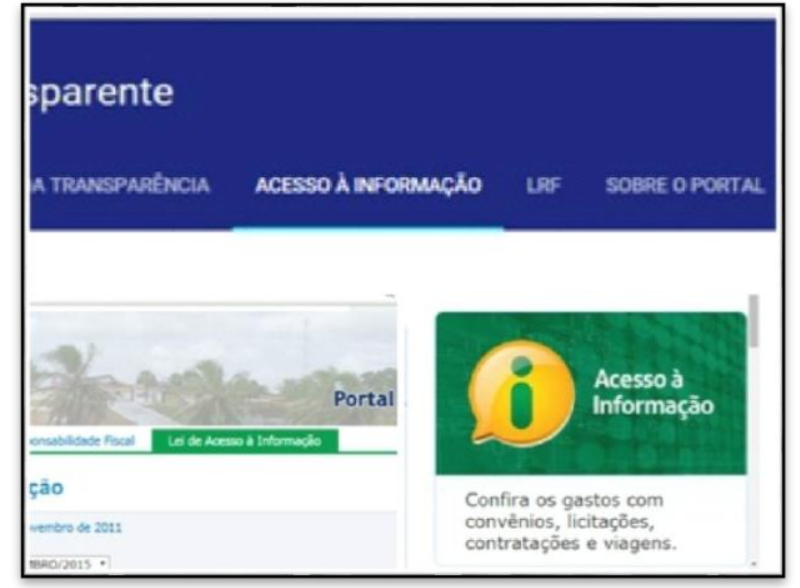

\section{Figura 1 - Links com a nomenclatura "Acesso à Informação" localizados nos sítios pesquisados.}

Fonte: Elaborada pelos autores (2015).

A questão 4 buscou verificar se os municípios disponibilizaram na internet a Lei ou Decreto Municipal que regulamenta o direito de acesso à informação em âmbito local. Em nenhum dos sete municípios foi localizada essa legislação disponível eletronicamente para a consulta dos cidadãos, uma vez que é por esse instrumento onde deverão ser obrigatoriamente regulamentadas os requisitos mínimos do sítio oficial, o Serviço de Informação ao Cidadão - SIC da prefeitura, os prazos para o cidadão interpor recurso quando houver negativa de acesso e as definições de informações sigilosas e pessoais. Tornar pública a normativa local na internet facilita o exercício do cidadão ao direito de acesso à informação, uma vez que o cidadão passa a conhecer, dentre outros pontos, quais os procedimentos para solicitar informações de forma presencial ou eletrônica, os prazos para a obtenção da resposta pelo órgão e para a 
interposição de recursos, como também de quais informações possivelmente terá o acesso parcial ou a negativa de acesso, em virtude do grau de sigilo ou por se tratar de informações pessoais. Por não haver localizado a norma local regulamentadora da LAI de cada município, a questão 5, que se tratava da definição dos critérios para a classificação e proteção de informações sigilosas e pessoais, obteve $100 \%$ de descumprimento. $\mathrm{O}$ art. 30, incisos I e II da LAI prevê que a autoridade máxima de cada órgão deverá publicar, anualmente, no sítio eletrônico oficial, o rol das informações que tenham sido desclassificadas nos últimos 12 (doze) meses; o rol de documentos classificados em cada grau de sigilo, com identificação para referência futura.

As questões 6 e 7 dizem respeito à divulgação de metas, indicadores e dados para o acompanhamento e avaliação dos programas, ações, projetos e obras do Poder Executivo Municipal. Nos dois quesitos, houve o cumprimento de apenas $29 \%$ dos municípios avaliados. No quesito 6, as metas e indicadores foram encontrados no Plano Plurianual e nas Leis Orçamentárias. Por sua vez, no quesito 7, o acesso aos dados para o acompanhamento de programas, ações, projetos e obras somente foi possível consultando os Relatórios Resumidos de Execução Orçamentária - RREO e Relatório de Gestão Fiscal - RGF. Todavia, muitos ainda sentem dificuldade em localizar estas informações nos referidos documentos, justamente por não haver indicação clara de que essas informações possam estar ali presentes, como também haver o predomínio da linguagem técnica jurídico-contábil, sendo que o recomendável seria elaborar o Relatório de Gestão, onde essas informações ficariam dispostas de modo simplificado, com o emprego da linguagem cidadã, que facilitasse o entendimento do cidadão comum.

As perguntas 8, 9 e 10 referem-se às inspeções, auditorias, prestação e tomada de contas pelos órgãos de controle interno e externo. Os índices foram muito baixos de cumprimento, onde nenhum dos municípios tornou público o acesso aos relatórios de inspeções e auditorias, como também às prestações e tomadas de contas realizadas pelos órgãos de controle interno e externo. No entanto, apenas $27 \%$ dos municípios do Mato Grande divulgam as prestações de contas de exercícios anteriores, mediante a publicação dos relatórios contábeis obrigatórios pela LRF. Embora também sejam exigências da Lei de Responsabilidade Fiscal, a maioria dos portais pesquisados apenas divulga informações acerca das receitas e despesas do órgão. Já aqueles que divulgam as prestações de contas de exercícios anteriores o fazem de maneira incompleta, uma vez que a prestação de contas anual do Poder Executivo Municipal é submetida à fiscalização e auditoria dos órgãos de controle interno e externo, cujos pareceres tornam-se parte integrante da prestação de contas final e que também deveria ser amplamente divulgado.

$\mathrm{Na}$ questão 11, a resposta "sim" seria marcada se o sítio apresentasse informações referentes aos procedimentos licitatórios, incluindo os respectivos editais, resultados e os contratos celebrados. Em apenas um município foi localizado um link "Licitação", que direcionava aos links apenas com os editais de cada certame. No entanto, para se ter acesso ao arquivo do edital, era necessário realizar um cadastro para fazer o download do mesmo. Deste modo, foi considerado o não cumprimento deste 
quesito, integralizando o percentual de $100 \%$ de descumprimento pelos municípios pesquisados.

$\mathrm{Na}$ questão 13, o índice de respostas afirmativas ao quesito "respostas às perguntas mais frequentes da sociedade" também foi baixo, com apenas 14\% dos sítios pesquisados. No entanto, foi observado um maior índice de cumprimento nas questões 12 e 14, referente, respectivamente, ao registro das competências e estrutura organizacional, endereços e telefones das respectivas unidades e horários de atendimento ao público; e à disponibilização de ferramenta de pesquisa de conteúdo, que alcançaram cada uma, 57\% de observância pelos municípios.

As perguntas 15 e 16 discorrem sobre a obrigação de divulgar informações sobre os repasses ou transferências de recursos financeiros e o registro das despesas. Nestes itens, houve o cumprimento de $100 \%$ das prefeituras, as quais disponibilizaram estas informações em seus respectivos Portais da Transparência, onde não somente observaram o disposto na Lei de Acesso à Informação, como também os dispositivos da Lei de Responsabilidade Fiscal.

A possibilidade de gravação de relatórios em diversos formatos eletrônicos, tais como planilha e texto, o qual foi o tema da questão 17 , obteve um percentual de $71 \%$ de respostas "sim". Os principais formatos encontrados foram o CSV (Comma Separated Values) e o PDF (Portable Document Format). Na $18^{\mathrm{a}}$ questão, 86\% dos sítios possibilitam o acesso dos dados de forma automatizada por sistemas externos estruturados e legíveis por máquina, ou seja, refere-se ao tipo de acesso em que não haja obstáculos à leitura de arquivos, tais como senhas e captchas. No entanto, todos descumpriram o item 19, da divulgação detalhada da estrutura da informação no sítio, o qual facilitaria a navegação do usuário caso estivesse presente, por servir de guia para encontrar as principais informações divulgadas pela prefeitura, em observância à LAI.

Em relação à qualidade das informações publicadas, no item 20 , foi observado que em $100 \%$ dos sítios e portais, foi garantida a autenticidade e integridade das informações. Mas, na questão 21, em 29\% dos municípios pesquisados, as informações não são atualizadas, como por exemplo, as informações sobre a execução orçamentária, onde a última atualização foi realizada em 2013 ou 2014. As informações incompletas e desatualizadas, além de indicar a falta de compromisso com a transparência, também inviabiliza o exercício do controle social.

A questão 22 diz respeito aos mecanismos presentes no sítio ou portal que proporcionem a acessibilidade da informação a todos os usuários, inclusive aos portadores de deficiência. Foi observado que, em nenhum dos sítios e portais da transparência pesquisados, houve o cumprimento deste item. Deste modo, para a adequação dos sítios e portais, recomenda-se observar o Modelo de Acessibilidade em Governo Eletrônico (e-MAG), que foi elaborada nos termos do art. 17 da Lei $\mathrm{n}^{\circ} 10.098$, de 19 de dezembro de 2000, e do art. $9^{\circ}$ da Convenção sobre os Direitos das Pessoas com Deficiência, aprovada pelo Decreto Legislativo no 186, de 9 de julho de 2008.

Finalizando o checklist, temos as questões 23 e 24, que tratam, respectivamente, da indicação do endereço, telefone e instruções para o contato eletrônico ou telefônico com o órgão; e a alternativa de encaminhamento de pedidos de acesso pela internet. No 
item 23, em $43 \%$ dos sítios e portais pesquisados, encontravam-se disponíveis o endereço e o telefone da instituição, enquanto que, em relação ao item 24 , apenas $14 \%$ dos municípios disponibiliza de um espaço em seu sítio oficial para receber solicitações dos usuários. No entanto, pode-se constatar que ambiente eletrônico disponibilizado não se constitui exatamente em um e-SIC, como nos padrões utilizados pelo Poder Executivo Federal, mas de uma ouvidoria. Também foi observado que, nos sítios eletrônicos, não há instruções à população sobre os procedimentos para requerer informações no setor de Serviço de Informações ao Cidadão - SIC da prefeitura.

\section{CONSIDERAÇÕES FINAIS}

A efetivação do princípio da transparência na administração pública, mediante a disponibilização de informações na internet, deve ser encarada com muita seriedade, por se tratar de uma garantia do direito fundamental do cidadão de acesso às informações públicas, o qual é reconhecido em diversos dispositivos legais e normativos.

O presente estudo teve como objetivo analisar os sítios eletrônicos oficiais e portais da transparência mantidos pelas prefeituras de sete municípios da região do Mato Grande/RN, quanto ao cumprimento da Lei de Acesso à Informação. Foi aplicado um questionário, com 24 questões, baseadas nos artigos $6^{\mathrm{a}}$ ao $10^{\circ}$ da LAI, para se chegar a um índice de cumprimento aos requisitos mínimos de transparência ativa, mediante a disponibilização de informações na internet.

Pelos resultados encontrados, foi constatada a dificuldade dos municípios em se cumprir os requisitos mínimos da LAI, uma vez que apenas 2 das 7 prefeituras pesquisadas obtiveram índices acima de 50\%, sendo o máximo atingido pelo município de Poço Branco, com o índice de 58\%. Na outra ponta, foi o município de João Câmara quem obteve o menor índice de cumprimento, correspondente a apenas $25 \%$. Pode-se inferir que, mesmo com a intensa fiscalização do Ministério Público Estadual e do Tribunal de Contas do Estado, fechando o cerco contra as prefeituras para que cumpram as determinações da lei, os sítios eletrônicos pesquisados neste artigo seguem a LAI de maneira superficial, certificada pela falta de alguns conteúdos exigidos na lei ou pela desatualização dos dados.

Ao analisar os resultados de cada um dos 24 itens, pode-se verificar que apenas 4 foram atendidos integralmente pelos municípios os quesitos referentes à disponibilização do Portal da Transparência, da divulgação dos repasses ou transferências, do registro das despesas e a autenticidade e integridade das informações divulgadas. O cumprimento integral destes itens se deve ao fato de que os municípios sofrem cobranças dos órgãos de controle e fiscalização, respaldadas não somente na LAI, mas também em outras legislações, como a Lei de Responsabilidade Fiscal e sua posterior alteração (Lei Complementar nº 131/2009).

No entanto, 7 itens foram aferidos com $100 \%$ de descumprimento. Em todos os sítios eletrônicos pesquisados, não foram localizadas a Lei ou Decreto Municipal que 
regulamenta o acesso à informação no âmbito local, a classificação das informações sigilosas e pessoais, os resultados de inspeções e auditorias, as prestações e tomadas de contas efetuadas pelos órgãos de controle interno e externo, os procedimentos licitatórios, o detalhamento do formato de estruturação das informações e a acessibilidade. Esta dificuldade pode ser explicada pela resistência dos agentes públicos em relação ao processo de mudança da cultura de sigilo para a cultura de acesso, pela prevalência da ideia de que as informações produzidas e custodiadas pelos órgãos públicos são de propriedade dos agentes públicos que o produziram.

No entanto, há de se reconhecer que a LAI é uma norma recente, que traz consigo a necessidade de realizar grandes mudanças organizacionais nas repartições públicas, cujo processo gera altos custos para a entidade, com o treinamento de pessoal, o fortalecimento das tecnologias de informação e as ações de conscientização dos agentes públicos. Mas, a situação financeira dos municípios de pequeno porte, onde se enquadra os municípios pesquisados neste artigo, bem como as barreiras impostas pela cultura de sigilo ainda predominante no âmbito do poder público, impedem a efetiva adequação à LAI em um curto espaço de tempo.

Por essa razão é que os sítios eletrônicos oficiais pesquisados atendem parcialmente aos requisitos mínimos da lei. Durante a pesquisa, vários foram os casos encontrados onde as informações foram disponibilizadas de modo inteligível ao cidadão comum, como, por exemplo, requerendo um conhecimento de finanças públicas para compreender as informações dispostas nos demonstrativos e relatórios de execução orçamentária. Verifica-se, portanto, que houve a preocupação em dar publicidade aos atos administrativos, mas sem o compromisso com a transparência das informações públicas, ficando esta apenas no discurso político dos gestores municipais.

Assim, pode-se concluir que as prefeituras municipais da região do Mato Grande/RN ainda não estão preparadas para atender a demanda da sociedade por informações públicas. Isto se deve não somente aos problemas administrativos e operacionais, mas também pela ausência da cultura de acesso nessas entidades. Por outro lado, o cidadão, diante da dificuldade de acesso às informações públicas, deverá evitar o comodismo e fazer a sua parte, exercendo o controle social ao acompanhar os sítios eletrônicos, a fim de observar seu cumprimento legal, analisar a transparência das informações disponibilizadas e exigir dos órgãos públicos a divulgação máxima das informações públicas.

Recomenda-se, portanto, outros estudos sobre o tema, como a análise das dificuldades de implementação da LAI, a análise da evolução do direito de acesso à informação assegurada pela Lei $\mathrm{n}^{\circ}$. 12.527/2011 e levantamento da satisfação dos usuários quanto à utilização das ferramentas da LAI, para identificar falhas e necessidades de melhoria dos mesmos. 


\section{REFERÊNCIAS}

1. ALMADA, Maria Paula; CARREIRO, Rodrigo. A Qualidade da Informação Pública: Uma Análise do Grau de Transparência dos Portais de Cinco Estados Brasileiros. In: Simpósio em Tecnologias Digitais e Sociabilidade: Performances Interacionais e Mediações Sociotécnicas. Salvador, Bahia, Brasil, 10-11 outubro 2013.

2. AMORIM, Michelle Ribeiro Lage de; SILVA, Felipe de Souza da.Impactos da Implantação da Lei de Acesso à Informação no Serviço Público Brasileiro. In: Congresso Internacional de Administração. Ponta Grossa, Paraná, Brasil, 22-26 setembro 2014.

3. ANDI \& Artigo 19. Acesso à informação e controle social das políticas públicas; coordenado por Guilherme Canela e Solano Nascimento. Brasília, DF: ANDI; Artigo 19, 2009.

4. ANGÉLICO, Fabiano. Lei de acesso à informação pública e seus possíveis desdobramentos à accountability democrática no Brasil. 2012. 133 f.Dissertação (Mestrado em Administração Pública e Governo) - Escola de Administração de Empresas de São Paulo, Fundação Getúlio Vargas, São Paulo, 2012.

5. BERNARDES, Marciele Berger; SANTOS, Paloma Maria; ROVER, Aires José. Ranking das prefeituras da região Sul do Brasil: uma avaliação a partir de critérios estabelecidos na Lei de Acesso à Informação. Revista de Administração Pública, v. 49, n. 3, p. 761-792, maio/jun. 2015.

6. BRASIL. Constituição da República Federativa do Brasil: texto constitucional promulgado em 05 de outubro de 1988... Brasília, Senado Federal, Subsecretaria de Edições Técnicas, 2010.

7. . Lei $\mathrm{n}^{\circ} .8 .159$, de 08 de janeiro de 1991. Dispõe sobre a política nacional de arquivos públicos e privados e dá outras providências.

8. . Lei $\mathrm{n}^{\circ} .9 .507$, de 12 de novembro de 1997. Regula o direito de acesso a informações e disciplina o rito processual do habeas data.

9. Lei $\mathrm{n}^{\circ}$. 9.784, de 29 de janeiro de 1999. Regula o processo administrativo no âmbito da Administração Pública Federal.

10. Lei Complementar $n^{\circ} .101$, de 04 de maio de 2000. Estabelece normas de finanças públicas voltadas para a responsabilidade na gestão fiscal e dá outras providências.

11.

Lei Complementar $n^{\circ}$. 131, de 27 de maio de 2009.Acrescenta dispositivos à Lei Complementar $\mathrm{n}^{\mathrm{0}}$ 101, de 4 de maio de 2000, que estabelece normas de finanças públicas voltadas para a responsabilidade na gestão fiscal e dá outras providências.

12. Lei $n^{\circ}$. 12.527, de 18 de novembro de 2011. Regula o acesso a informações previsto no inciso XXXIII do art. 5ำ no inciso II do $\S 3^{\circ}$ do art. 37 e no $\S 2^{\circ}$ do art. 216 da Constituição Federal; altera a Lei no 8.112, de 11 de dezembro 
de 1990; revoga a Lei $\mathrm{n}^{\mathrm{o}}$ 11.111, de 5 de maio de 2005, e dispositivos da Lei no 8.159 , de 8 de janeiro de 1991; e dá outras providências.

13.

Decreto $\mathrm{n}^{\mathrm{o}}$. 7.724, de 16 de maio de 2012. Regulamenta a Lei $\mathrm{n}^{\mathrm{o}}$ 12.527, de 18 de novembro de 2011, que dispõe sobre o acesso a informações previsto no inciso XXXIII do caput do art. $5^{\circ}$, no inciso II do $\S 3^{\circ}$ do art. 37 e no $\S$ $2^{\circ}$ do art. 216 da Constituição.

14. CAVALCANTI, Joyce Mariella Medeiros; DAMASCENO, Larissa Mayara da Silva; SOUZA NETO, Manoel Veras de. Observância da lei de acesso à informação pelas autarquias federais do Brasil. Perspectivas em Ciência da Informação, v.18, n.4, p.112-126, out./dez. 2013.

15. CONTROLADORIA GERAL DA UNIÃO. Cartilha Acesso à Informação Pública: uma introdução à Lei no . 12.527, de 18 de novembro de 2011. Brasília, 2011. dos órgãos e entidades estaduais e municipais. Brasília, 2013.

17. Curso Rumo a uma cultura de acesso à informação: a Lei 12.527/2011 - Escola Virtual da CGU, 2015.

18. IBGE. Censo Demográfico 2010.2 Disponível em: <http://www.censo2010.ibge.gov.br>. Acesso em 15 maio 2015.

19. MATIAS-PEREIRA, José. Manual de gestão pública contemporânea. São Paulo:Atlas, 2008.

20. MENDEL, Toby. Liberdade de informação: um estudo de direito comparado. $2^{\mathrm{a}}$ Edição. Brasília: UNESCO, 2009.

21. MINISTÉRIO DO DESENVOLVIMENTO AGRÁRIO. Plano Territorial de Desenvolvimento Rural Sustentável. Brasília, 2010. Disponível em: <http://sit.mda.gov.br/download/ptdrs/ptdrs_qua_territorio055.pdf >. Acesso em 15 maio 2015.

22. PLATT NETO, Orion Augusto. et al. Publicidade e transparência das contas públicas: obrigatoriedade e abrangência desses princípios na administração pública brasileira. Revista de Contabilidade Vista \& Revista, v. 18, n. 1, p. 75-94, jan./mar. 2007.

23. RESENDE, Walisson da Costa; NASSIF, Mônica Erichsen. Aplicação da lei de acesso à informação em portais de transparência governamentais brasileiros. Encontros Bibli: Revista Eletrônica de Biblioteconomia e Ciência da Informação, v. 20, n. 42, p. 1-16, jan./abr., 2015.

24. SALES, Tainah Simões. Acesso à Informação, Controle Social das Finanças Públicas eDemocracia: Análise dos Portais da Transparência dos Estados Brasileiros Antes e Após o Advento da Lei no 12.527/2011. Direito Público, v. 1, $n^{\circ} .48$, p. 28-48, nov./dez. 2012.

25. SANTOS, Luiz Alberto dos. Prestação de contas, acesso a informação eparticipação e processo decisório governamental. In: X Congreso Internacional del CLAD sobre La Reforma del Estado y de la Administración Pública. Santiago, Chile, 18 - 21, Oct. 2005. 
26. ZANELLA, Liane Carly Hermes. Metodologia de estudo e de pesquisa em administração. $2^{\mathrm{a}}$ ed. reimpr. Florianópolis: Departamento de Ciências da Administração/UFSC; [Brasília]: CAPES: UAB, 2012. 